\title{
Caffeic Acid Phenethyl Ester Prevents Mesengial Cell Apoptosis by Suppressing p38MAPK Signal
}

\section{Emine Mamal', Murat Basar', Hafize Uzun² and Ismail Seckin ${ }^{1 *}$}

${ }^{1}$ University of Istanbul, Cerrahpasa Medical Faculty, Department of Histology and Embryology, Turkey

${ }^{2}$ University of Istanbul, Cerrahpasa Medical Faculty, Department of Biochemistry, Turkey

\begin{abstract}
Background: Nitric oxide (NO), synthesis from L-arginine by Nitric oxide synthesizes (NOS) at kidney mesangial cells and involved in functional kidney defects such as acute kidney failure, inflammatory nephritis, diabetic nephropathy. CAPE (Caffeic acid phenethyl ester) is natural antioxidant which has anti-inflammatory, anti-tumor affects. In this study we investigated effects of NO on rat kidney and therapeutic and protective effects of CAPE.

Methods: We used albino Wistar rats, weigh 150-200. Our experimental groups: 1) Control 2) L-arginine-given group 3) Preventative group (L-arginine and CAPE administered together) 4) Therapeutic group (after L-arginine administration; CAPE administered 7 days) ( $n=10 /$ per group). Kidney tissues harvested and cortex region divided into two in order to perform western blot and immunohistochemistry. p38MAPK and active caspase-3 levels investigated with western blot and we performed p38MAPK immunohistochemistry. Differences between groups were calculated by means of one-way ANOVA and $p<0.05$ were considered to be statistically significant.
\end{abstract}

Results: In L-arginine applied group p38MAPK level increased significantly, when compared to control and preventative group $(p<0.001)$. On the other hand there were no statistical significance between control and preventative group $(p<0.057)$. Additionally $\mathrm{p38MAPK}$ level increased in therapeutic group compared to control and preventative group $(p<0.001)$. Moreover, in L-arginine-given group active caspase-3 level significantly increased compared to control and preventative group $(p<0.05)$. However, active caspase-3 level in preventative group significantly decreased compared to therapeutic group $(p<0.05)$.

Conclusions: These results suggest that excess NO generation activates p38MAPK signaling pathway and triggers apoptosis in the kidney mesangial cells. Additionally, CAPE inhibits L-arginine's effect and prevents mesangial cell apoptosis.

Keywords: CAPE; p38MAPK; Mesangial cell; Apoptosis

\section{Introduction}

Endogenous L-arginine synthesis is takes place at kidney glomerulus [1]. L-arginine is well known material used in the protein synthesis for transport, storage and excretion of nitrous products. Particularly, $\mathrm{L}$-arginine is main substance of guanidine products such as creatinine and methylguanidine which are considered as uremic toxins. These $\mathrm{L}$-arginine metabolites are occupied in renal pathophysiology. Nitric oxide $(\mathrm{NO})$ is formed in the process of oxidation of L-arginine in cytoplasm and act as a secondary messenger. NO is involved in the modulation of renal hemodynamic, regulation of renal tubular and glomerular functions in the kidney [2-4]. Excess NO is locally produced and damages the kidney. The NO produced by excess arginine as well as the creatine and methylguanidin is the major factor to kidney injury $[5,6]$.

MAPKs compose a family of protein kinases, whose function and regulation have been conserved during evolution [7]. The MAPK superfamily consists of three well-characterized subfamilies; ERK, p38 MAPK and JNK [8]. The p38 MAPK family consists of four isoforms, $\alpha$, $\beta, \gamma$ and $\delta$, which are activated by several stimuli, including hormones, ligands, inflammatory cytokines such as IL- $1 \beta$ and TNF- $\alpha$, and stresses on such as UV radiation, osmotic and heat shock [9]. The downstream activities of p38 MAPK include cytokine production, apoptosis, cellcycle arrest, regulation of RNA splicing or stabilization, and cell differentiation [10].

Protective effects of natural antioxidants against drug-induced toxicities gain more importance, especially when free radical generations are involved. Caffeic acid phenethyl ester (CAPE), a phenolic antioxidant derived from the propolis of honeybee hives, is currently being used in a number of natural health products.

CAPE has been shown to have anti-tumor [11], anti-inflammatory $[12,13]$, antiviral [14] and immunomodulatory properties [15].

In this study we investigated the antioxidative effects of CAPE on rat mesangial cells with L-arginine induced excess NO.

\section{Materials and Methods}

\section{Chemicals}

All chemicals were obtained from Sigma Chemical Inc. (St. Louis, MO, USA) and all organic solvents from Merck Chemical Inc. (Darmstadt, Germany). All reagents were of analytical grade. All reagents except the tris-buffered saline were prepared each day and stored in a refrigerator at $4^{\circ} \mathrm{C}$.

*Corresponding author: Ismail Seckin, Professor, Department of Histology and Embryology, Cerrahpasa Medical Faculty, University of Istanbul, Cerrahpasa, 34098, Istanbul, Turkey, Tel: +90-212-414-3000/21623; Fax: +90-212-414-3026; E-mail: ismail.seckin@yahoo.com

Received July 19, 2012; Accepted September 26, 2012; Published Septembe 28, 2012

Citation: Mamal E, Basar M, Uzun H, Seckin I (2012) Caffeic Acid Phenethyl Ester Prevents Mesengial Cell Apoptosis by Suppressing p38MAPK Signal. J Cytol Histol 3:155. doi:10.4172/2157-7099.1000155

Copyright: ( 2012 Mamal E, et al. This is an open-access article distributed under the terms of the Creative Commons Attribution License, which permits unrestricted use, distribution, and reproduction in any medium, provided the original author and source are credited. 


\section{Animal model}

Forty male Spraque-Dawley rats (8-week old, 150-200 g) obtained from University of Istanbul Laboratory Animal Production Unit was used in the study. The animals were procedure, maintained and used in accordance with the "Animal Welfare Act and the Guide for the Care and Use of Laboratory animals prepared by the University of Istanbul, Animal Ethical Committee". They were kept in an environment of controlled temperature $\left(24-26^{\circ} \mathrm{C}\right)$, humidity $(55-60 \%)$, and controlled photoperiod ( $12 \mathrm{~h}$ of light and $12 \mathrm{~h}$ of dark) for one week before the start of experiment. Rats had free access to water and balanced diet was provided ad libitum.

\section{Experimental design}

The rats used in the study were randomly grouped (10 each) as follows:

a) Sham-operated control animals were injected with $0.1 \%$ DMSO solution. These animals were also placed in the same environmental room conditions as the exposure groups.

b) As described rats were treated with L-arginine in drinking water (2\%) for 3 weeks followed by $0.1 \%$ DMSO solution injection for 7 days (L-arginine-given) [16].

c) L-arginine+CAPE treated rats. CAPE was treated $\left(10 \mu \mathrm{Mkg}^{-1} \mathrm{day}^{-1}\right)$ i.p. for 3 weeks (preventative group).

d) Following to L-arginine treatment (3 weeks), CAPE was treated $\left(10 \mu \mathrm{Mkg}^{-1} \mathrm{day}^{-1}\right) 7$ days (therapeutic group).

\section{Determination of oxidative stress parameters}

After experimental procedure animals were sacrificed by cervical dislocation and blood samples were collected by cardiac puncture to evaluate serum Superoxide dismutase (SOD; Cell Biolabs Inc., San Diego, CA USA), malonyl dialdehyde (MDA; Cell Biolabs Inc., San Diego, CA USA) and nitric oxide (NO; Cell Biolabs Inc., San Diego, CA USA) levels according to manufacturer's instruction.

\section{Immunohistochemistry}

p38MAPK and phospho-p38MAPK immunostaining was performed as described previously [17]. Briefly, $5 \mu \mathrm{m}$ formalin-fixed, paraffin-embedded kidney sections were deparaffinized in xylene and rehydrated through a descending ethanol series. Antigen retrieval was then performed by boiling the slides in citrate buffer $(10 \mathrm{mM}$; $\mathrm{pH}$ 6.0) for $15 \mathrm{~min}$, followed by endogenous peroxidase quenching with $3 \%$ hydrogen peroxide (in 50\% methanol/50\% distilled water) for $15 \mathrm{~min}$. The slides were then incubated with 5\% blocking goat serum (Vector Labs, Burlingame, CA) in Tris-buffered saline (TBS) for $30 \mathrm{~min}$ at room temperature in a humidified chamber. Excess serum was then removed, and serial sections were incubated with either rabbit polyclonal p38MAPK (Cell Signaling Technology Inc., Beverly, MA) at 1:200 dilution in TBS and phospho specific p38MAPK (Cell Signaling Technology Inc., Beverly, MA) at 1:200 dilution in TBS, overnight in a humidified chamber at $4^{\circ} \mathrm{C}$. Non-specific rabbit IgG isotype antibody was used at the same concentrations as the primary antibodies for negative controls. After washing, the slides were incubated with biotinylated goat anti-rabbit secondary antibody (Vector Labs) at 1:400 dilutions for $30 \mathrm{~min}$ at room temperature. After washing again in TBS, the antigen-antibody complex was detected with an avidin-biotin peroxidase kit (Vector Labs). Diaminobenzidine (3, 3-diaminobenzidine tetrahydrochloride dehydrate) was used as the chromogens to detect p38MAPK and phosphor specific p38MAPK immunoreactivity. Slides were then counterstained with hematoxylin and mounted.

The intensity of total and phosphorylated p38MAPK immunostainings were semi-quantitatively evaluated using HSCORE analysis. Immunostaining intensity was categorized into the following scores: 0 (no staining), 1 (weak, but detectable, staining), 2 (moderate staining), and $3+$ (intense staining). An HSCORE value was derived for each specimen by calculating the sum of the percentage of cells that stained at each intensity category multiplied by its respective intensity score, using the formula HSCORE $=\Sigma \mathrm{i}\left(\mathrm{i}^{\star} \mathrm{Pi}\right)$, where ' $\mathrm{i}$ ' represents the intensity category score, and 'Pi' is the corresponding percentage of cells [17]. For each slide, five different fields were evaluated microscopically at 200X magnification. HSCORE evaluation was performed independently by two investigators blinded to the source of the samples; the average score of both was then used.

\section{Western blot analysis}

Control and treated kidney glomeruli isolated by differential sieving [18] ( $>75 \%$ of the isolated glomeruli were decapsulated) and homogenized in buffer (1\% Triton X100, $150 \mathrm{mM} \mathrm{NaCl}, 20 \mathrm{mM}$ Tris, 2 mMEDTA with proteaseinhibitor at $\mathrm{pH} 8$ ). Total protein was determined by a detergent-compatible protein assay (Bio-Rad, Hercules, CA). Samples $(40 \mu \mathrm{g})$ were loaded on $10 \%$ Tris- $\mathrm{HCl}$ Ready Gels (Bio-Rad), electrophoretically separated, and electroblotted onto nitrocellulose membrane (Bio-Rad). The membrane was blocked with 5\% nonfat dry milk in TBS containing $0.1 \%$ Tween 20 (TBS-T) for $1 \mathrm{~h}$ to reduce nonspecific binding. Subsequently, the membrane was incubated for 2 $\mathrm{h}$ with primary antibodies against total and phosphorylated p38 MAPK [polyclonal rabbit p38 MAPK and polyclonal rabbit phospho-specific p38 MAPK, both at 1:1000 dilution, in 2\% nonfat dry milk in TBS-T (Cell Signaling Technology)] and polyclonal rabbit active caspase-3 (1:500 dilution, in 5\% nonfat dry milk in TBS-T). The membrane was washed with TBS-T for $1 \mathrm{~h}$ and incubated with horseradish peroxidaseconjugated anti-rabbit secondary antibody (Vector Labs) diluted at 1:10000 in TBS-T. The protein was visualized by light emission on film (Amersham Biosciences, Buckinghamshire, UK) with enhanced chemiluminescence substrate (Amersham Biosciences). Immunoblot bands for active caspase-3, total and phosphorylated p38 MAPK were quantified using a laser densitometer.

\section{Statistical analysis}

Data was presented as means \pm SEM. A computer program (SigmaPlot 11.0, San Jose, CA, USA) was used for statistical analysis. Differences between groups were calculated by means of one-way ANOVA followed by the Student-Newman-Keuls post hoc test. In all comparisons, statistical significance was defined as $\mathrm{p}<0.05$.

\section{Results}

\section{Water and L-arginine intake}

Total water intake was $14-17 \mathrm{~mL} / \mathrm{rat} /$ day. There was no significant increase in fluid intake between experimental groups (Table 1).

\section{Serum MDA, SOD and NO levels}

L-arginine treatment significantly increased serum NO levels (30,34 $\pm 1,2$ Mean \pm SEM; Table 2). Preventative CAPE treatment (21,9 $\pm 0,87)$, but not therapeutic use of CAPE $(23,92 \pm 0,75)$, significantly reduced serum NO levels (Table 2). Additionally in L-argininegiven group serum MDA levels $(4,1 \pm 0,12)$ were significantly higher 
Citation: Mamal E, Basar M, Uzun H, Seckin I (2012) Caffeic Acid Phenethyl Ester Prevents Mesengial Cell Apoptosis by Suppressing p38MAPK Signal. J Cytol Histol 3:155. doi:10.4172/2157-7099.1000155

\begin{tabular}{|l|l|}
\hline & Water Intake \\
\hline Control & $14 \mathrm{~mL} /$ rat/day \\
\hline L-Arginine & $16 \mathrm{~mL} /$ rat/day \\
\hline Preventative & $17 \mathrm{~mL} /$ rat/day \\
\hline Therapeutic & $16 \mathrm{~mL} /$ rat/day \\
\hline
\end{tabular}

Table 1: Total water intake. There was no significant increase in fluid intake between experimental groups.

\begin{tabular}{|l|l|l|l|l|l|}
\hline & Control & L-Arginine & Preventative & Therapeutic & P value \\
\hline NO & $19,85 \pm 0,6$ & $30,34 \pm 1,2 \dagger$ & $21,9 \pm 0,87$ & $23,92 \pm 0,75$ & $<0,001$ \\
\hline MDA & $2,79 \pm 0,09 *$ & $4,1 \pm 0,12$ & $3,02 \pm 0,13 *$ & $3,56 \pm 0,2$ & $<0,001$ \\
\hline SOD & $25,18 \pm 0,5 *$ & $18,9 \pm 0,8$ & $24,5 \pm 0,6 *$ & $21,5 \pm 0,7$ & $<0,001$ \\
\hline
\end{tabular}

† vs Control, Preventitive and Therapeutic; * vs L-Arginine and Therapeutic Table 2: Serum NO, MDA and SOD levels.

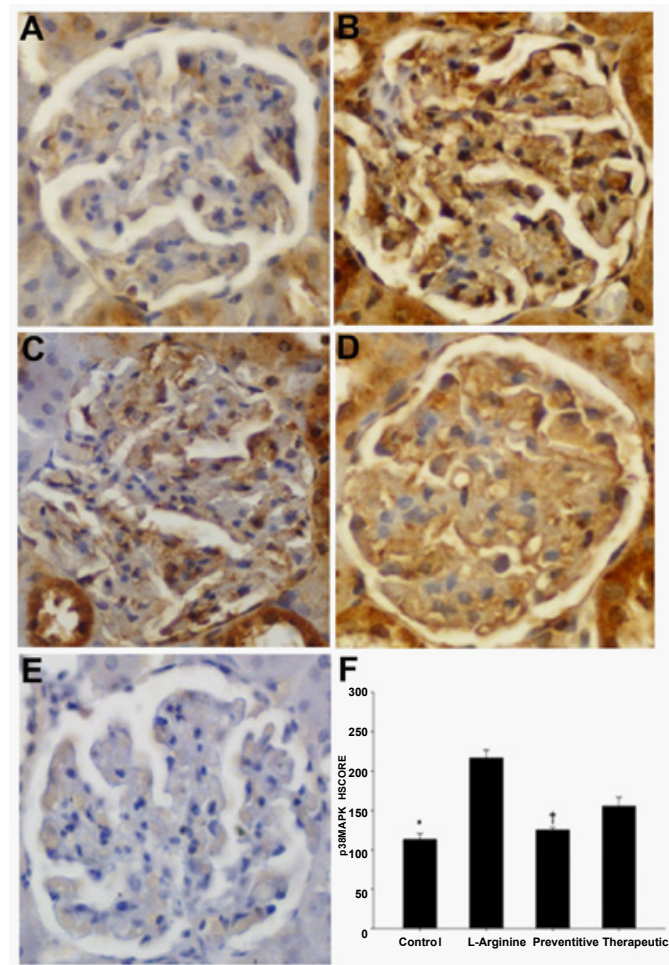

Figure 1: Immunohistochemical analysis of phospho-p38MAPK expression in control, L-Arginine-given, preventative and therapeutic group mesangial cells. Representative micrographs of serial sections from control (A); L-arginine-given (B); preventative $(C)$ and therapeutic (D) specimens are shown. Phospho-p38MAPK immunostaining (brown) in mesangial cells was mostly cytoplasmic. Between groups, phosphop38MAPK immunostaining was greater in L-arginine-given (B) vs. control (A) and preventative $(C)$ mesangial cells, while there was no significant difference among L-arginine-given and therapeutic (D) group. PhosphoP38MAPK intensity HSCOREs in control, preventative and L-argininegiven specimens (mean \pm SEM) are shown $(F)$; * vs. L-arginine-given and therapeutic mesangial cells; $\dagger$ vs. L-arginine-given and therapeutic mesangial cells; $p<0.05$. Parallel staining with a rabbit isotype was used as a negative control for phospho-p38MAPK antibody (E).

compared to control $(2,79 \pm 0,09)$ and preventative group $(3,02 \pm 0,13$; Table 1). Furthermore, there were no significance between L-argininegiven and therapeutic group $(3,56 \pm 0,2)$. On the other hand, serum SOD levels were significantly higher in control $(25,18 \pm 0,5)$ and preventative group $(24,5 \pm 0,6)$ compared to L-arginine $(18,9 \pm 0,8)$ and therapeutic group $(21,5 \pm 0,7$; Table 2$)$.

\section{Effects of L-arginine and CAPE on the phosphorylation of p38MAPK in kidney mesangial cells}

Control, L-arginine treated, preventative and therapeutic kidneys were immunostained for total- and phospo-p38MAPK (Figure 1). HSCORE analysis revealed that immunoreactivity for phosphop38MAPK (brown) was significantly greater in the cytoplasm of mesangial cells from L-arginine treated tissues (Figure. 1B) compared with control (Figure 1A) specimens (mean \pm SEM HSCORE: 216,88 $\pm 5,08$ vs. $113,13 \pm 3,07$, respectively, $\mathrm{P}<0.05$; Figure $1 \mathrm{~F}$ ). However, phospho-p38MAPK HSOCREs were not significantly different in control (Figure 1A) and preventative tissues (Figure 1C; mean \pm SEM HSCORE: $216,88 \pm 5,08$ vs. $113,13 \pm 3,07$, respectively, $\mathrm{p}<0.05)$. (Figure 1D and 1E). Consistent with the p38MAPK HSCORE analysis presented above, p38MAPK phosphorylation was significantly higher in L-arginine treated group compared to control and preventative group ( $<<0,05$; Figure 2 ). Again consistent with the HSCORE analysis there was no significant difference between control and preventative group (Figure 2, $\mathrm{p}>0,05$ ). The total p38 MAPK levels did not show any change with any of the treatments.

\section{Determination of active caspase- 3 Levels}

Active Caspase-3 western blot analysis revealed that in the preventative group active caspase- 3 expression was significantly decreased in kidney mesangial cells compared to therapeutic and $\mathrm{L}$-arginine-given group (Figure $3, \mathrm{p}<0.001$ ). On the other hand, there were no difference between therapeutic and L-arginine treated group (Figure 3, $\mathrm{p}>0.05$ ).

\section{Discussion}

Our study revealed that L-arginine induced excess NO generation leads mesangial cells to apoptosis through p38MAPK signaling pathway and CAPE, if used as preventative but not as therapeutic, could prevent this damaging effect of excess NO and renal failure. We investigated the effect of CAPE on L-arginine induced apoptosis in mesangial cell, and found that CAPE; if used as preventative, protect mesangial cells from $\mathrm{L}$-arginine induced apoptosis.

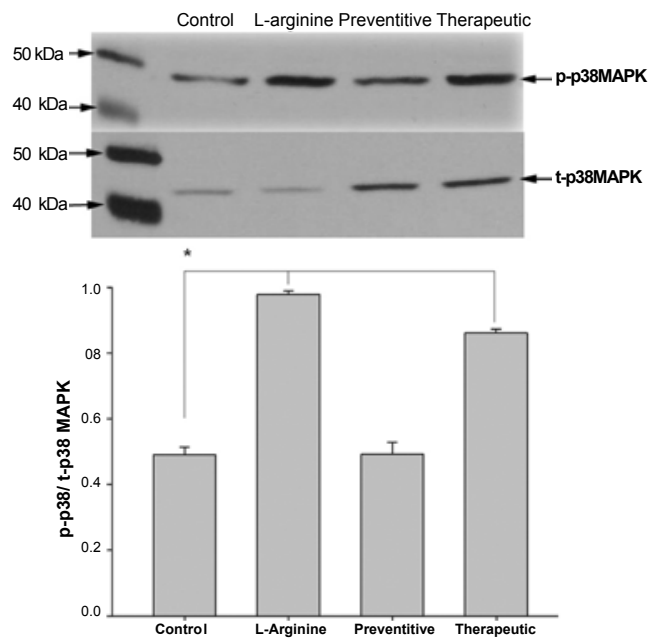

Figure 2: Western blot analysis of phopho- and total-p38MAPK. Control and treated kidneys were homogenized in buffer and subjected to sodium dodecyl sulfate-polyacrilamide gel electrophoresis and Western blotting. Bars represent mean \pm SEM of phospho-p38MAPK/total p38MAPK levels $(n=10)$. * versus $L$-arginine-given and therapeutic; $p<0.05$. 
Citation: Mamal E, Basar M, Uzun H, Seckin I (2012) Caffeic Acid Phenethyl Ester Prevents Mesengial Cell Apoptosis by Suppressing p38MAPK Signal. J Cytol Histol 3:155. doi:10.4172/2157-7099.1000155

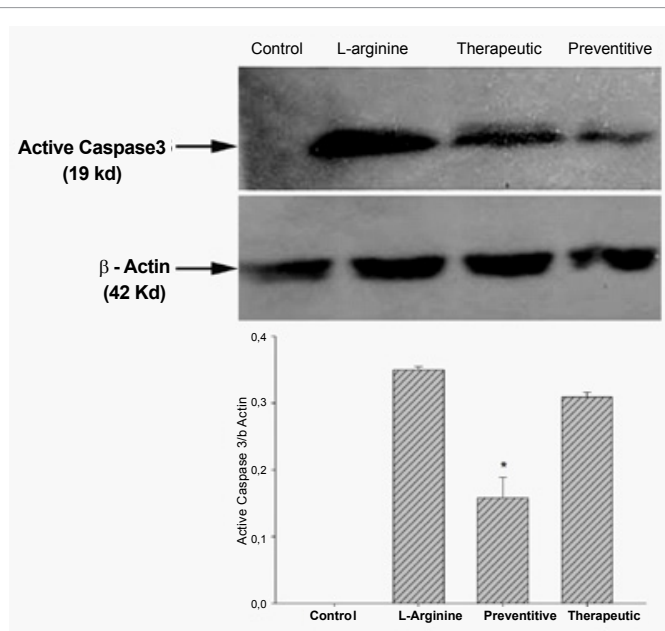

Figure 3: Western blot analysis of active caspase-3, apoptosis indicator, levels. Control and treated kidneys were homogenized in buffer and subjected to sodium dodecyl sulfate-polyacrilamide gel electrophoresis and western blotting. Bars represent mean \pm SEM of active caspase- 3 levels $(n=10) .{ }^{*}$ versus $L$-arginine-given and therapeutic; $p<0.001$.

Excessive dietary arginine evokes renal failure by increasing the production of NO in the kidney. Sandau K et al. showed that L-arginine could lead mesangial cell apoptosis and MAPK signaling involved in this process [19-21]. In the present study the administration of excess $\mathrm{L}$-arginine increased the concentration of $\mathrm{NO}$, evokes apoptosis of mesangial cells by increasing p38MAPK expression. Noris et al. [22] reported that arginine levels and NO synthesis were higher in uremic patients than in healthy persons and this data suggest us an explanation for the increased NO synthesis in uremia. Also, in the present study, nitric oxide level was higher in arginine-given group than in control group. It raises the possibility that the increase in NO production may be attributable to dietary arginine and that it may cause renal injury.

Therefore, if CAPE used as preventative suppresses the production of $\mathrm{NO}$ and it would be predicted to ameliorate the renal injury induced by excessive arginine. Furthermore, CAPE has a potent scavenging effect through the inhibition of oxidative stress-induced apoptosis [23]. Yokozawa et al. [24] reported that excessive arginine affected the activity of antioxidative enzymes in the renal peroxisomes and the reductions in the SOD and catalase activities induced by arginine imply that reactive oxygen species were generated and the immune system was weakened. In the present study CAPE inhibited p38MAPK signaling by suppressing NO production and prevents mesangial cell apoptosis.

In summary, CAPE might play a crucial role of NO inhibition as free radical scavenging effect. In addition, it was found to ameliorate apoptotic effect of L-arginine in mesangial cells, which suggests that CAPE can protect renal cells against oxidative injury and apoptosis by suppressing p38MAPK signaling.

\section{Acknowledgment}

This study was kindly supported by a grant to Emine Mamal from Istanbul University Scientific Research Projects \#1642. Mamal et al.

Financial Support: This work was supported by grant from the Istanbul University Scientific Research Projects \#1642 (to Emine Mamal).

\section{References}

1. Natelson S, Sherwin JE (1979) Proposed mechanism for urea nitrogen reutilization: relationship between urea and proposed guanidine cycles. Clin Chem 25: 1343-1344.
2. Ito $S$, Ren $Y$ (1993) Evidence for the role of nitric oxide in macula densa control of glomerular hemodynamics. J Clin Invest 92: 1093-1098.

3. Radermacher J, Klanke B, Schurek HJ, Stolte HF, Frölich JC (1992) Importance of NO/EDRF for glomerular and tubular function: studies in the isolated perfused rat kidney. Kidney Int 41: 1549-1559.

4. Shultz PJ, Schorer AE, Raij L (1990) Effects of endothelium-derived relaxing factor and nitric oxide on rat mesangial cells. Am J Physiol 258: F162-167.

5. Orita Y, Tsubakihara Y, Ando A, Nakata K, Takamitsu Y, et al. (1978) Effect of arginine or creatinine administration on the urinary excretion of methylguanidine. Nephron 22: 328-336.

6. Paller MS, Hoidal JR, Ferris TF (1984) Oxygen free radicals in ischemic acute renal failure in the rat. J Clin Invest 74: 1156-1164.

7. Widmann C, Gibson S, Jarpe MB, Johnson GL (1999) Mitogen-activated protein kinase: conservation of a three-kinase module from yeast to human Physiol Rev 79: 143-180

8. Chang L, Karin M (2001) Mammalian MAP kinase signalling cascades. Nature 410: $37-40$.

9. Johnson GL, Lapadat R (2002) Mitogen-activated protein kinase pathways mediated by ERK, JNK, and p38 protein kinases. Science 298: 1911-1912.

10. Olson JM, Hallahan AR (2004) p38 MAP kinase: a convergence point in cancer therapy. Trends Mol Med 10: 125-129.

11. Chiao C, Carothers AM, Grunberger D, Solomon G, Preston GA, et al. (1995) Apoptosis and altered redox state induced by caffeic acid phenethyl ester (CAPE) in transformed rat fibroblast cells. Cancer Res 55: 3576-3583.

12. Michaluart P, Masferrer JL, Carothers AM, Subbaramaiah K, Zweifel BS, et al. (1999) Inhibitory effects of caffeic acid phenethyl ester on the activity and expression of cyclooxygenase-2 in human oral epithelial cells and in a rat model of inflammation. Cancer Res 59: 2347-2352

13. Orban Z, Mitsiades N, Burke TR Jr, Tsokos M, Chrousos GP (2000) Caffeic acid phenethyl ester induces leukocyte apoptosis, modulates nuclear factor-kappa B and suppresses acute inflammation. Neuroimmunomodulation 7: 99-105.

14. Burke TR Jr, Fesen MR, Mazumder A, Wang J, Carothers AM, et al. (1995) Hydroxylated aromatic inhibitors of HIV-1 integrase. J Med Chem 38: 41714178.

15. Natarajan K, Singh S, Burke TR Jr, Grunberger D, Aggarwal BB (1996) Caffeic acid phenethyl ester is a potent and specific inhibitor of activation of nuclear transcription factor NF-kappa B. Proc Natl Acad Sci U S A 93: 9090-9095.

16. Koppelmann T, Pollak Y, Mogilner J, Bejar J, Coran AG, et al. (2012) Dietary L-arginine supplementation reduces Methotrexate-induced intestinal mucosal injury in rat. BMC Gastroenterol 12: 41.

17. Basar M, Yen CF, Buchwalder LF, Murk W, Huang SJ, et al. (2010) Preeclampsia-related increase of interleukin-11 expression in human decidual cells. Reproduction 140: 605-612.

18. Salant DJ, Cybulsky AV (1988) Experimental glomerulonephritis. Methods Enzymol 162: 421-461.

19. Sandau K, Pfeilschifter J, Brune B (1997) The balance between nitric oxide and superoxide determines apoptotic and necrotic death of rat mesangial cells. $J$ Immunol 158: 4938-4946.

20. Sandau K, Pfeilschifter J, Brüne B (1997) Nitric oxide and superoxide induced p53 and Bax accumulation during mesangial cell apoptosis. Kidney Int 52: 378386.

21. Sandau KB, Callsen D, Brüne B (1999) Protection against nitric oxide-induced apoptosis in rat mesangial cells demands mitogen-activated protein kinases and reduced glutathione. Mol Pharmacol 56: 744-751.

22. Noris M, Benigni A, Boccardo P, Aiello S, Gaspari F, et al. (1993) Enhanced nitric oxide synthesis in uremia: implications for platelet dysfunction and dialysis hypotension. Kidney Int 44: 445-450.

23. Ozguner F, Oktem F, Armagan A, Yilmaz R, Koyu A, et al. (2005) Comparative analysis of the protective effects of melatonin and caffeic acid phenethyl ester (CAPE) on mobile phone-induced renal impairment in rat. Mol Cell Biochem 276: 31-37.

24. Yokozawa T, Cho EJ, Nakagawa T (2003) Influence of green tea polypheno in rats with arginine-induced renal failure. J Agric Food Chem 51: 2421-2425. 